\title{
Influence of Indian Ocean high pressure on streamflow variability over southwestern Australia
}

\author{
Saqib-Ur-Rehman
}

Iqra University, Department of Computer Science, North Nazimabad, Karachi, Pakistan

\author{
Article history \\ Received August 16, 2013; accepted January 8, 2014. \\ Subject classification: \\ El Niño southern oscillation, Indian Ocean high pressure, Indian Ocean high longitude, Southern oscillation index.
}

\section{ABSTRACT}

The seasonal and interannual variability of the southwestern Australia streamflow was examined based on re-analysis dataset from the National Centers for Environmental Prediction / National Center for Atmospheric Research, plus monthly streamflow data from 17 meteorological stations obtained from the Department of Water of the Australian Water Resource Council (1976-2008). Significant findings reveal that since the middle of the last century, the early winter (May-August) streamflow variability over southwestern Australia has been associated with variability in the intensity of the Indian Ocean high pressure (IOHP) system, as well as the zonal movement of the high pressure system across the Indian Ocean. Of note, however, the emphasis in the previous studies has linked the ongoing winter drought in western Australia to changes in sea level pressure, both on a local basis and over larger areas. We introduce objective indices for the area-weighted pressure of the IOHP, and the IOHP area-weighted latitude (IOHLT) and longitude (IOHLN) positions. When the IOHP is shifted to the east, there is less streamflow in the southwestern Australian rivers that are examined in this study. The situation is reversed when the IOHP is shifted to the west, when there is more streamflow in the southwestern Australian rivers. The characteristics of the streamflow pattern are determined for the river catchment areas located around the coastal region over southwestern Australia using principal component analysis. The first principal component taken into consideration describes $84.43 \%$ of the total variance. The multiple correlation between the loading of the first principal component scores of the streamflow and the IOHP and IOHLN is 0.54, while the correlation between the southern oscillation index is 0.44. Centers of action indices explain $29 \%$ of the streamflow variability, while the southern oscillation index explains only of the $19 \%$ streamflow variability. This discovery is of real importance for the definition of the physical mechanism of seasonal (May-August) streamflow variability of southwestern Australian and the IOHP.

\section{Introduction}

A nexus has been developed between the El Niño southern oscillation (ENSO) activity and climate change throughout many parts of the world [e.g., Ropelewski and Halpert 1987, 1989, Glantz et al. 1991, Dettinger and Diaz 2000]. Rainfall and streamflow fluctuations have mainly been attributed to the ENSO activity across disparate spatio-temporal scales. The streamflow - that is an integrator of the rainfall over a large area - is, therefore, linked with the ENSO [Western Australian Department of Water 2009] activity. This suggests one important use of ENSO in forecasting streamflow. However, we argue here that Indian Ocean High Pressure (IOHP) is more important a factor to be considered in analyzing the variations in streamflow.

Exposure of the streamflow to the ENSO has been explored for a number of rivers [Kahya and Dracup 1993, Simpson et al. 1993, Dracup and Kahya 1994, Piechota and Dracup 1996, Amarasekera et al. 1997, Piechota et al. 1997, Uvo and Graham 1998, Wang and Eltahir 1999, Kahya and Karabork 2001]. To develop a link between the ENSO and climate, several circulation indices have been used. Previous studies that have investigated these ENSO effects have used a wide range of methods to categorize periods, such as El Niño, La Niña and neutral episodes. Chiew and McMahon [2003] explored the worldwide ENSO-streamflow teleconnection through the installation of a first harmonic to the 24-month El Niño streamflow segments from 581 catchment areas across the world.

Recently, the 'centers of action' (COA) approach has been shown to be useful in investigations of a number of regional phenomena. Winter rainfall in southwestern and western Australia is significantly influenced by the IOHP [Rehman and Iqbal 2011]. The early winter streamflow in the Donnelly River in southwestern Australia has closer correlation with the pressure and longitude position than with the ENSO [Rehman and Iqbal 2011]. Interannual variability of the Gulf Stream northwall position has a closer correlation with the longitude position of the Icelandic low pressure than with 
the North Atlantic oscillation [Hameed and Piontkovski 2004]. The variability of the transport of Saharan dust to the tropical Atlantic Ocean in winter has a closer correlation with the latitude position of the Azores high pressure than with the North Atlantic oscillation [Riemer et al. 2006] and the transport of dust to the Caribbean islands in summer is governed by the longitude of the Azores high pressure [Doherty et al. 2008].

The main objective of the present study was to use the COA approach to analyze the influence of the IOHP early winter (May-August) streamflow variability in the major rivers of the southwest coastal division of southwestern Australia. Multivariate statistical analysis was carried out using principal component analysis (PCA) for important catchment areas of the rivers of the southwest coastal division. The PCA describes the spatial and temporal variations in the streamflow patterns from 1976 to 2008. The study also compares the correlations of the ENSO and the COA indices with the streamflow. Finally, we provide the physical justification through which the atmospheric circulation over the Indian Ocean and its spatial and temporal patterns are discussed, providing support for the claim raised in this study.

\section{Data description and methods}

The monthly streamflow data used in this study were obtained from the Department of Water of the Australian Water Resources Council. The dataset was developed using topography-resolving analysis methods applied to all available streamflow station data that passed a series of internal quality tests. The stations that have the longest records available, from 1976 to 2008, were used in this study (see Table 1). The monthly mean gridded sea level pressure (MSLP) data used in this study were obtained from the National Centers for Environmental Prediction (NCEP) re-analysis [Kalnay et al. 1996] for calculating the objective $\mathrm{COA}$ indices for the monthly mean IOHP, IOHLT and IOHLN, as described by Hameed and Piontkovski [2004]. Other global climate indices, such as, Multivariate ENSO index (MEI), were obtained from the NCEP (www.cpc.ncep.noaa.gov). For easy comparisons between the rainfall and the streamflow, the streamflow data were normalized by dividing them according to their catchment area. To remove linear trends from interannual variation of the streamflow, we applied detrending processes, which allowed the removal of a linear trend of the original streamflow data.

\section{Center of action methodology}

An estimate of the influence of atmospheric pressure fluctuations on rainfall variability over Australia can be attained through quantitative assessment of the fluctuations in the pressure and locations of the IOHP.
The pressure index $\mathrm{I}_{\mathrm{p}}$ of a high pressure system can be defined as an area-weighted pressure departure from a threshold value over the domain $(I, J)$, as given in Equation (1), and as suggested by Santer [1988] and Hameed et al. [1995]:

$$
I_{p, \Delta t}=\frac{\sum_{i=1}^{I} \sum_{j=1}^{J}\left(P_{i j, \Delta t}-P_{t}\right) \cos \phi_{i j} \delta_{i j, \Delta t}}{\sum_{i=1}^{I} \sum_{j=1}^{J} \cos \phi_{i j} \delta_{i j, \Delta t}}
$$

where $P_{i j, \Delta t}$ is the SLP at grid reference $(i, j)$ as the mean over a time interval $\Delta t$. In this case, the MSLP values were taken from the NCEP re-analysis, $P_{t}$ is the threshold SLP value (for the IOHP, $P_{t}=1016 \mathrm{hPa}$,), $\phi_{i j}$ is the latitude of the grid point $(i, j) . \delta=1$ if $\left(P_{i j, \Delta t}-P_{t}\right)>0$, and $\delta=0$ if $\left(P_{i j, \Delta t}-P_{t}\right)<0$.

This threshold was selected based upon observations that values above $1016 \mathrm{hPa}$ tend to isolate regions of local pressure maxima over subtropical and mid-latitude regions of the Indian Ocean and adjacent land areas. This ensures that the pressure difference is due to the high pressure system. The intensity is thus a measure of the anomaly of the atmospheric mass over the section $(I, J)$. The domain of the IOHP was chosen as $10^{\circ} \mathrm{S}$ to $45^{\circ} \mathrm{S}$, and $40^{\circ} \mathrm{E}$ to $120^{\circ} \mathrm{E}$.

The domain of the IOHP was chosen by examining the geographical ranges in the NCEP re-analysis data over the period from 1976 to 2008.

Similarly, the latitudinal index was defined as in Equation (2):

$$
I_{\phi, \Delta t}=\frac{\sum_{i=1}^{I} \sum_{j=1}^{J}\left(P_{i j, \Delta t}-P_{t}\right) \phi_{i j} \cos \phi_{i j} \delta_{i j, \Delta t}}{\sum_{i=1}^{I} \sum_{j=1}^{J}\left(P_{i j, \Delta t}-P_{t}\right) \cos \phi_{i j} \delta_{i j, \Delta t}}
$$

and the longitudinal index $I_{\lambda, \Delta t}$ was defined in an analogous manner.

\section{Spatio-temporal analysis of streamflow variabil- ity using principal component analysis}

We examine the streamflow data using PCA, which is a multivariate statistical technique that is useful to reduce the dimensionality of large numbers of variables, and to interpret data in an appropriate manner. We analyzed the streamflow data of all of the stations that had the longest records available, to find the seasonal and annual variability for the period of 1976 to 2008. Our analysis focused only on the first principal component that cumulatively accounts for more than two-thirds of the variance, at approximate $84.43 \%$ of the total variance in the data. The rotation of the principal component is vital for precise interpretation in connection with domain shape, as described by Rich- 
man [1993], while others have countered that this rotation is only appropriate in common factor analysis, and that domain shape has little influence on the principal components [Legates 1993]. The varimax rotation is used on the first unrotated principal component score time series, to extract the maximum variance of the streamflow dataset of all of the stations included in this study (Figure 1). The first principal components, both rotated and unrotated, are highly correlated; the correlation coefficient of the first unrotated and rotated principal component scores of annual streamflow data is 0.96 . This leads us to believe that there is little different in the variance. Figure 2 illustrates the strongest correlation pattern for each station with the first principal component loading. It should be noted that a strong positive correlation coefficient is observed for all of the river catchment areas in the southwest coastal division. We observe that the maximum decline occurs in the Warren River, Donnelly River, Preston River, Harvey River and Swan coastal River, and along the Busselton coast. The mean component score is calculated on the seasonal and annual basis to determine the maximum

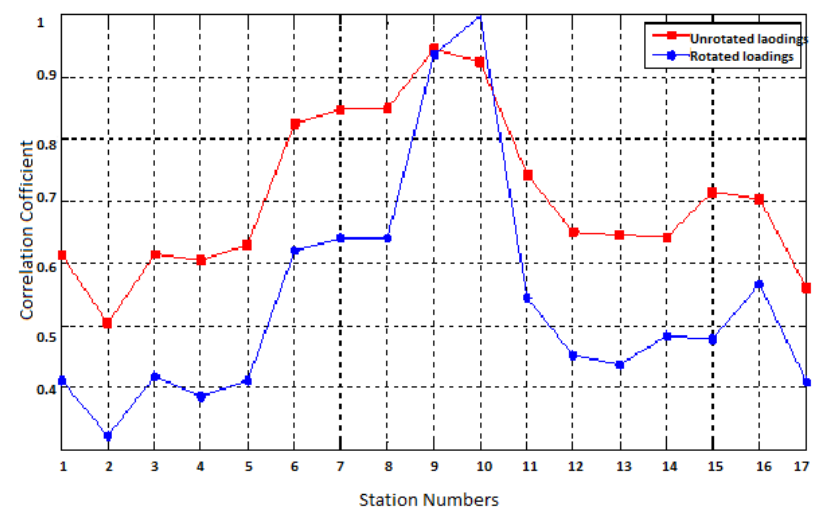

Figure 2. Correlation coefficients of the first unrotated versus rotated principal component of the annual streamflow, with the original streamflow data for all of the catchment areas that were used in this study.

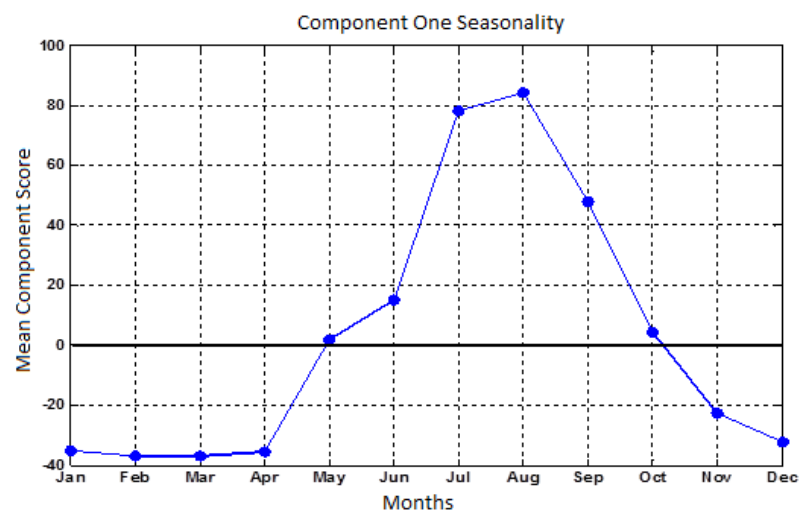

Figure 3. First principal component. Seasonal variation of the streamflow at the southwest coastal division for all of the catchment areas that were used in this study (from 1976 to 2008).

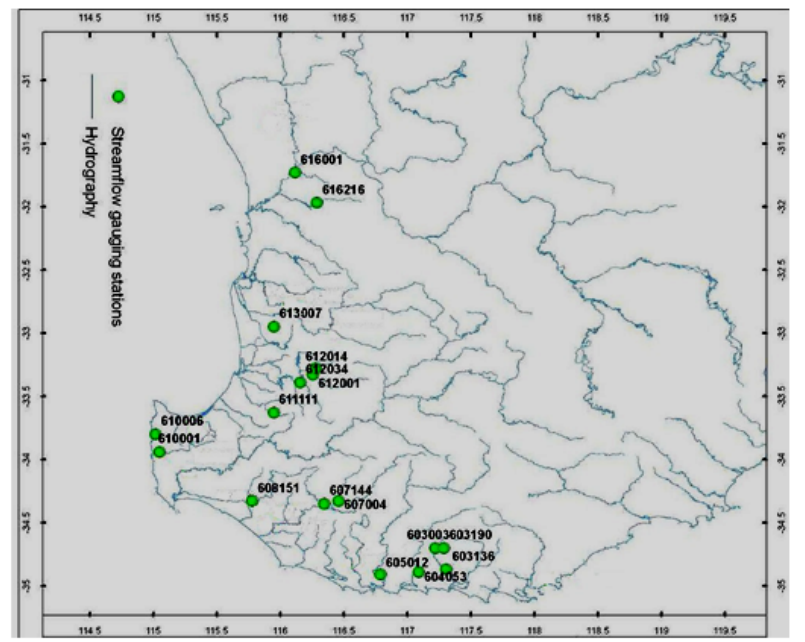

Figure 1. Streamflow stations of the southwest coastal division of Australia that were used in this study (source: Water Resources Management Division).

variance in the first principal component. The seasonality of the first component that is illustrated in Figure 3 reveals that the positive phase of this principal component explains the seasonality, and the yearly mean score is highest in July and August, which means that the maximum decrease occurs in the winter season. Figure 4 shows the annual observed and detrended streamflow time series of the principal component scores. The similar pattern of both of these time series shows that decreasing trends were seen in the southwest coastal division catchment areas from 1976 to 2008. The annual mean component scores of the time series (Figure 4) has become more prevalent in the last 33 years; however, the decrease is particularly apparent from 1976 to 2008, except for the 1990s decade. A trend line was best
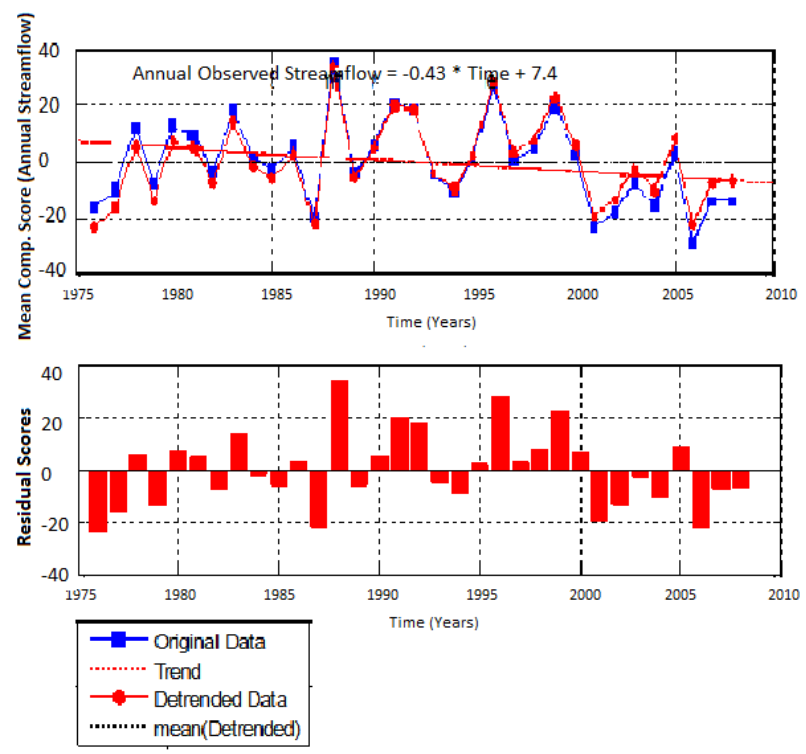

Figure 4. Annual observed and detrended streamflow mean component score time series of the first unrotated principal component scores of the southwest coastal division that were used in this study. The subplots show the residual scores. 
fitted to the annual mean component scores, which described a statistically significant negative slope of -0.43 . The residuals plot (Figure 4) describes the approxima-

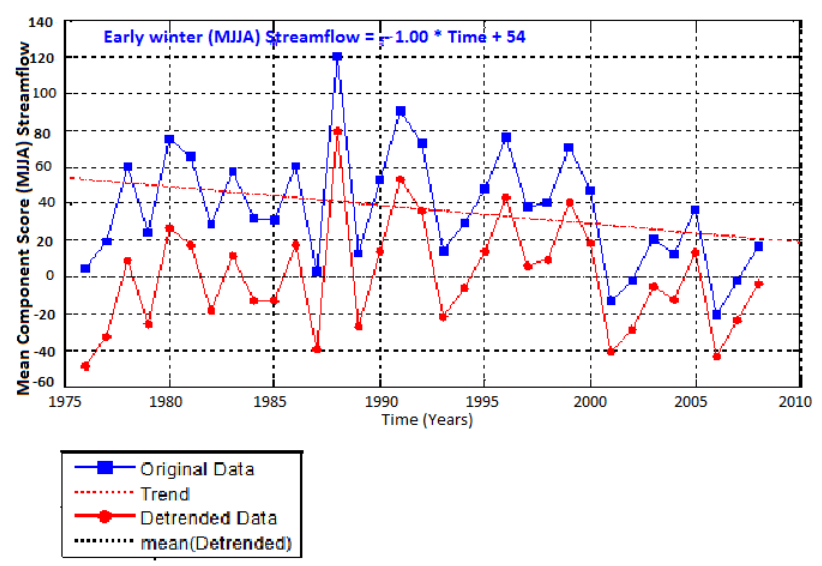

Figure 5. Early winter-time observed and detrended streamflow mean component score time series of the first unrotated principal scores of the southwest coastal division for all of the catchment areas that were used in this study. May-August.

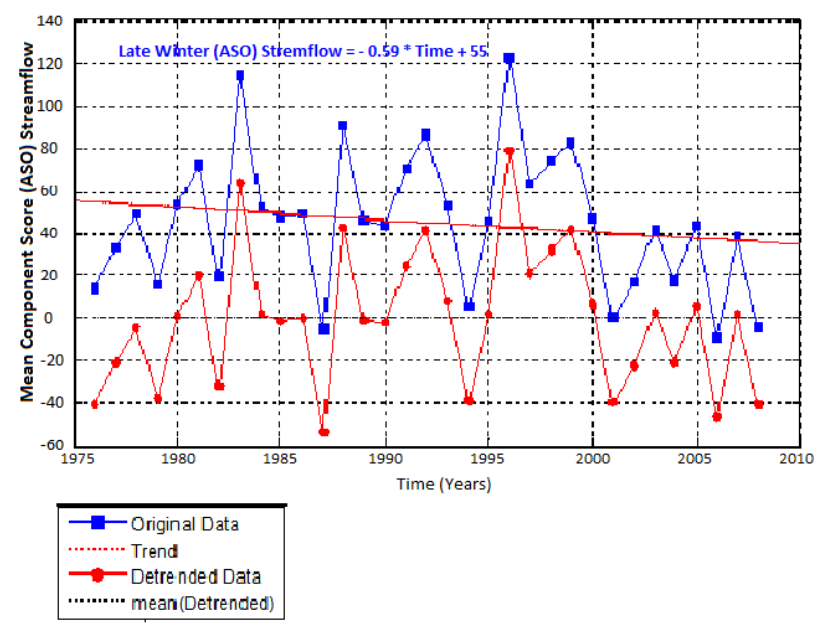

Figure 6. Late winter-time observed and detrended streamflow mean component score time series of the first unrotated principal scores of the southwest coastal division for all of the catchment areas that were used in this study. ASO, August, September, October.

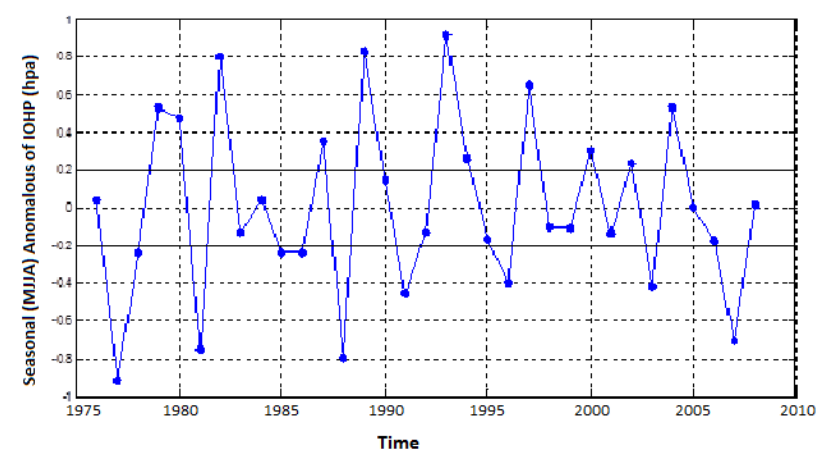

Figure 7. Anomalous time series of the early winter MCP of the $\operatorname{IOHP}\left(\mathrm{hPa} / \mathrm{month}^{-1}\right)$ over the Indian Ocean $\left(10^{\circ}-45^{\circ} \mathrm{S} ; 40^{\circ}-120^{\circ}\right.$ E) from 1976 to 2008, with standard deviations $\left(0.2 \mathrm{hPa}\right.$ month $\left.^{-1}\right)$. May-August. tion of the random errors. So the errors (residuals) show random behavior, which tells us that the model described the appropriate data attributes. On the contrary, if the errors (residuals) show seasonal behavior, we can see that the model does not fit the data appropriately. The rainfall decrease since the mid-20th century has been largely concentrated in the early part of the winter season, while the late winter rainfall (August-October) has not changed very much [IOCI 2004, Li et al. 2005]. The slope for the annual streamflow model during 19762008 (see Figure 4) is -0.43 . The slope of early winter (May-August) is found to be -1.0 (see Figure 5), and the slope in the case of late winter (August-October) is -0.59 (Figure 6). This significantly demonstrates that the most decreasing trend in the streamflow is observed during the early winter period. Therefore, we direct our attention to the streamflow variability in the early part of the winter (May-August). This useful information can also be used in estimation studies.

\section{Impact of IOHP and IOHLN on the streamflow variability}

The anomalies in Figure 7 describe the 10 winters when the mean central pressure (MCP) of the IOHP was at a minimum (more run-off observed in the southwest coastal division; in increasing order of the MCP of the IOHP: 1977, 1988, 1981, 2007, 1991, 1996, 2003 , $1985,1986,1978)$; and similarly, the 10 winters when the MCP of IOHP was at a maximum (less run-off observed in the southwest coastal division; in decreasing order of the MCP of the IOHP: 2002, 2000, 1987, 1980, 1979, 2004, 1997, 1982, 1989, 1993). However, this study reveals that the IOHP influenced the regional climate of western Australia, so we are concerned about the intensity of this high pressure across the Indian Ocean.

We also analyzed the influence of the eastward (IOHLN) and southward (IOHLT) shifts of the high pressure centers on the southwest coastal division runoff variability. The term IOHP has been frequently used in many studies [e.g., Hameed et al. 2011, Rehman and Iqbal 2011]. As shown in Figure 8a,b, during the early winters when the MCP of the IOHP was at a maximum, the component bar has the lowest mean principal component score, which shows that less streamflow occurred for the southwest coastal division. However, during the early winters when the MCP of the IOHP was at a minimum, there is a tendency towards the highest mean principal component scores that quantify the streamflow in the southwest coastal division.

The changes in the longitudinal position of the IOHP have a dominant influence on the streamflow in the southwest coastal division [Rehman and Iqbal 2011]. The streamflow pattern described in Figure 8c,d 


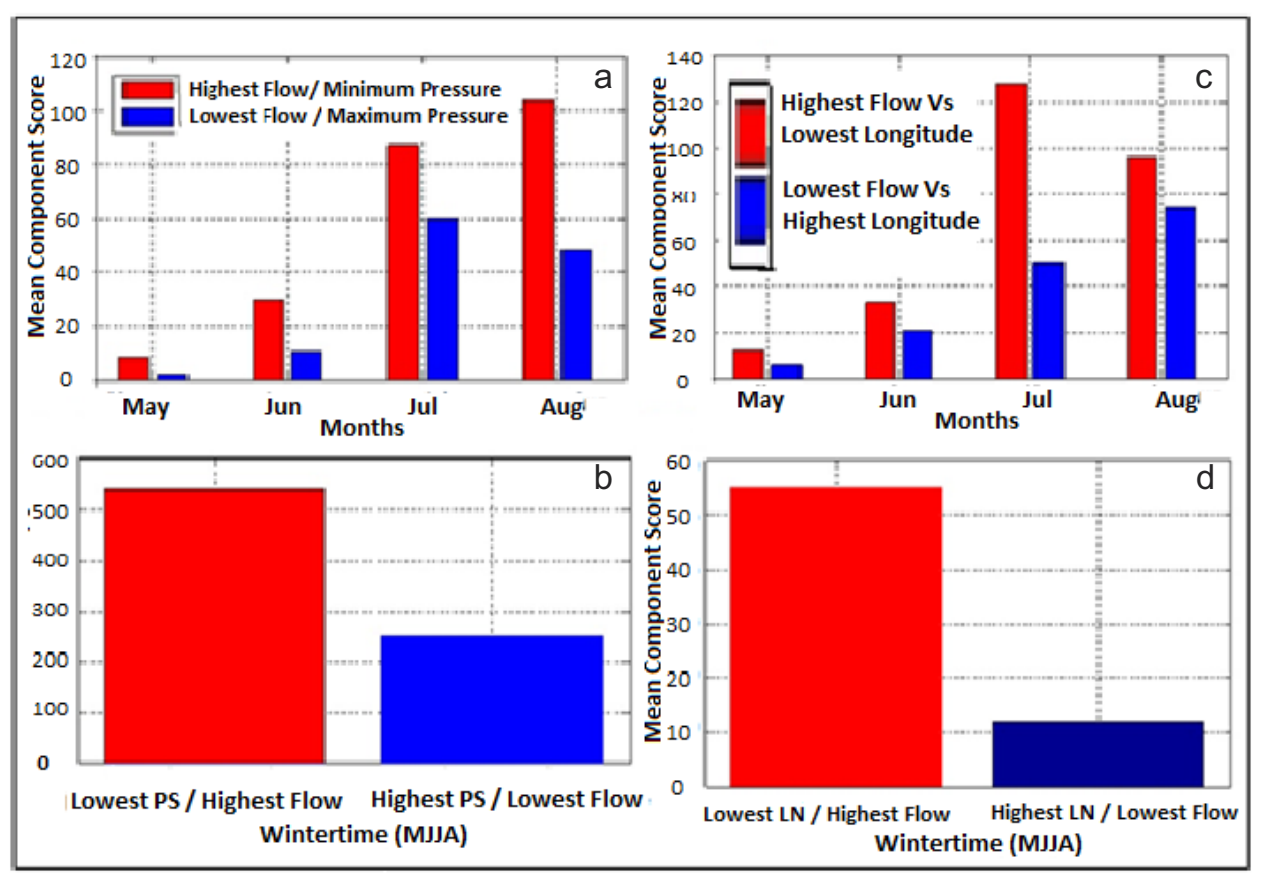

Figure 8. (a) The highest monthly streamflow occurred when the lowest monthly MCP of the IOHP was observed, and vice versa. (b) The highest early winter streamflow occurred when the lowest early winter MCP of the IOHP was observed, and vice versa. (c) The highest monthly streamflow occurred when the IOHLN shifted towards the west, and vice versa. (d) The highest early winter streamflow occurred when the IOHLN was shifted towards the west, and vice versa. May-August.

reveals that the southwest coastal division catchment area streamflow is significantly influenced by the zonal movement of the IOHP. When the IOHP shifted most towards the west, then the catchment areas had more streamflow. This situation was reversed when the IOHP shifted most towards the east, when the catchment area streamflow was reduced. The highest seasonal mean streamflow principal component score for May-August (early winter) was approximately 55 units, and the center of high pressure was located the most to the west, with the longitudinal position of the IOHP at $66.88^{\circ} \mathrm{E}$. Similarly, the minimum mean streamflow principal

\begin{tabular}{cccccc}
\hline $\begin{array}{c}\text { Station } \\
\mathrm{N}^{\circ}\end{array}$ & $\begin{array}{c}\text { Station } \\
\text { ID }\end{array}$ & $\begin{array}{c}\text { Longitude } \\
\left({ }^{\circ} \mathrm{E}\right)\end{array}$ & $\begin{array}{c}\text { Latitude } \\
\left({ }^{\circ} \mathrm{S}\right)\end{array}$ & River basin & $\begin{array}{c}\text { Catchment area } \\
\left(\mathrm{km}^{2}\right)\end{array}$ \\
\hline 1 & 603003 & 117.217 & 34.699 & 603 - Denmark Coast & 241.89 \\
2 & 603136 & 117.315 & -34.867 & 603 - Denmark Coast & 502.4 \\
3 & 603190 & 117.292 & -34.704 & 603 - Denmark Coast & 56.32 \\
4 & 604053 & 117.087 & -34.889 & 604 - Kent River & $1,806.04$ \\
5 & 605012 & 116.789 & -34.906 & 605 - Frankland River & $4,508.89$ \\
6 & 607004 & 116.459 & -34.331 & 607 - Warren River & 666.66 \\
7 & 607144 & 116.347 & -34.349 & 607 - Warren River & 460.53 \\
8 & 608151 & 115.785 & -34.327 & 608 - Donnelly River & 782.13 \\
9 & 610001 & 115.055 & -33.942 & 610 - Busselton coastal & 443 \\
10 & 610006 & 115.022 & -33.796 & 610 - Busselton coastal & 82.26 \\
11 & 611111 & 115.948 & -33.628 & 611 - Preston River & 102.1 \\
12 & 612001 & 116.263 & -33.33 & 612 - Collie River & $1,345.25$ \\
13 & 612014 & 116.276 & -33.278 & 612 - Collie River & 366.11 \\
14 & 612034 & 116.163 & -33.387 & 612 - Collie River & 661.62 \\
15 & 613007 & 115.948 & -32.946 & 613 - Harvey River & 13.57 \\
16 & 616001 & 116.116 & -31.734 & 616 - Swan coastal & 514.66 \\
17 & 616216 & 116.290 & -31.973 & 616 - Swan coastal & 590.91 \\
\hline
\end{tabular}

Table 1. Stream gauging stations with locations, river basin names and catchment areas. 
component score of approximately 11.45 units occurred when the center of the IOHP was located the most to the east, with the longitudinal position at $73.12^{\circ} \mathrm{E}$.

\section{Correlation analysis of streamflow in the south- west coastal division}

Table 2 shows the correlations between the streamflow mean principal component scores and the circulation indices. The correlation between the IOHP and the wintertime streamflow is -0.33 , which is significant at the $p<0.05$ confidence level. Similarly, the correlation between the wintertime streamflow mean principal component score and the IOHLN is -0.50 , which is also significant at the $p<0.05$ confidence level. These negative correlations imply that when the IOHP is shifted towards the east, there is less streamflow over the southwest coastal rivers, and vice versa. The correlation between the southern oscillation index (SOI) and the streamflow is 0.45 , which is significant at the $p<0.05$ confidence level. The correlation matrix for the COA indices and the ENSO indicators is shown in Table 3. We note that the IOHP and the IOHLN are mutually independent of each other, while the ENSO indicators are statistically significantly correlated with both the COA indices and the other ENSO indicators. An interesting question is whether the IOHP and IOHLN provide independent information about the streamflow in the southwest coastal division catchment areas. Therefore, we constructed a multilinear regression model for the winter-time streamflow (in mm), as in Equation (3):

$$
\begin{aligned}
& \text { Streamflow }= \\
& 15491-14.788 \mathrm{I}(\mathrm{IOHP})-5.247(\mathrm{IOHLN})
\end{aligned}
$$

With $R^{2}$ for this regression as 0.298 , this provides a significant improvement over the SOI $R^{2}$ of 0.193 . Hence the COA explains $29 \%$ of the streamflow variability, while the SOI explains only $19 \%$ of the streamflow variability.

\begin{tabular}{lcc}
\hline Parameter & $\begin{array}{c}\text { Mean principal component score for the } \\
\text { southwest coastal division }\end{array}$ \\
\cline { 2 - 3 } Time & Observed & Detrended \\
IOHP & -0.31 & 0.00 \\
IOHLN & -0.33 & -0.33 \\
MEI & -0.50 & -0.57 \\
NIÑO1,2 & -0.14 & -0.18 \\
NIÑO3 & -0.04 & -0.10 \\
NIÑO3.4 & -0.26 & -0.28 \\
NIÑO4 & -0.34 & -0.34 \\
SOI & -0.26 & -0.22 \\
IOHLT & 0.44 & 0.45 \\
IOHP and IOHLN & $0.54(29 \%)$ & 0.54 \\
\hline
\end{tabular}

Table 2. Correlation matrix for the May-August (early winter) streamflow mean principal component scores for the southwest coastal division catchment areas. IOHP, Indian Ocean high pressure; IOHLN, Indian Ocean high longitude; MEI, Multivariate ENSO index; NIÑO1, 2, 3, 3.4, 4, El Niño regions; SOI, southern oscillation index; IOHLT, Indian Ocean high latitude.

The forecasts can benefit considerably from the management of the water resources systems, particularly in Australia, where the streamflow variability is higher than elsewhere in the world [Ropelewski and Halpert 1987, Chiew and McMahon 2002, Chiew et al. 2003]. We calculated the lag correlations between the September-December streamflow principal component scores versus the May-August IOHP and SOI in the 17 catchment areas of the southwest coastal division, which are statistically significant at the $95 \%$ confidence level. The lag correlation between the streamflow and the IOHP is -0.45 , while the correlation between the streamflow and the SOI is 0.40 . The ENSO hydroclimate teleconnection is particularly strong in Australia, and it can be exploited to forecast the rainfall and streamflow for several months ahead [Chiew and McMahon

\begin{tabular}{|c|c|c|c|c|c|c|c|}
\hline \multirow[t]{2}{*}{ Parameter } & \multicolumn{7}{|c|}{ Parameter } \\
\hline & IOHP & IOHLN & MEI & NIÑO3 & NIÑO3.4 & NIÑO4 & NIÑO1,2 \\
\hline IOHLN & 0.1400 & & & & & & \\
\hline MEI & 0.4450 & 0.1580 & & & & & \\
\hline NIÑO3 & 0.3520 & 0.2220 & 0.8700 & & & & \\
\hline NIÑO3.4 & 0.3690 & 0.2500 & 0.8600 & 0.9040 & & & \\
\hline NIÑO4 & 0.4000 & 0.1220 & 0.8130 & 0.6840 & 0.8830 & & \\
\hline NIÑO1,2 & 0.2280 & 0.1490 & 0.7670 & 0.8610 & 0.6190 & 0.3900 & \\
\hline SOI & -0.4030 & -0.3350 & -0.8150 & -0.7270 & -0.8430 & -0.8080 & -0.4930 \\
\hline
\end{tabular}
2002]. Our calculations suggest that the IOHP has a

Table 3. Correlation matrix between the May-August (early winter) streamflow mean principal components for the southwest coastal division catchment areas. For abbreviations, see Table 2. 
similar lag correlation and can be used for an additional forecast streamflow in southwest western Australia. Therefore, when the run-off-IOHP has a strong connection, it can provide long lead-time forecasts in the southwest coastal division.

\section{Identification of the underlying factors in the re- lationship between the IOHP and the streamflow variability}

The above correlation and regression analysis provided casual relationships, so next we examined the NCEP observations and re-analysis data to determine the spatial patterns of the climate parameters associated with the extreme years of the IHOP, as shown in Figure 7. We provide physical justification using the NCEP re-analysis climate data of the MSLP and the vector winds. We also used monthly anticyclone frequency composite maps [Rehman 2012] to describe the anticyclone spatial distribution over the Indian Ocean. The monthly historical Australian rainfall data used in this study is based on a new high-resolution $\left(0.25^{\circ} \times\right.$ $0.25^{\circ}$ ) gridded dataset that has been developed by the Australian Bureau of Meteorology [Jones et al. 2009] to describe the spatial patterns of precipitation over southwest western Australia. All of the climate parameters were used to identify and examine the circulation pattern influence on the early winter (May-August) runoff from 1976 to 2008. Figure 7 describes the anomalous early winter time series of the MCP of the IOHP. A standard deviation of \pm 0.2 of the IOHP was used to define the anomalies of the 10 winters in which the IOHP was the lowest from 1976 to 2008. In increasing order of the MCP of the IOHP, these winters were for 1977, 1988, 1981, 2007, 1951, 1996, 2003, 1985, 1986 and 1978. For the 10 winters in which the IOHP was the highest from 1976 to 2008, in decreasing order of the MCP of the IOHP these were for 2002, 2000, 1987, 1980, 1979, 2004, 1997, 1982, 1989 and 1993.

\subsection{Rainfall spatial patterns}

Composite analysis of the early winter (May-August) mean precipitation (Figure 9a) showed distinctly different patterns for the 10 winters of the IOHP minimum in southwest western Australia. The seasonal mean rainfall across the western corner of southwest western Australia appeared as high values, with the mean of $180 \mathrm{~mm}$ centered at $116^{\circ} \mathrm{E}$ and $32-33^{\circ} \mathrm{S}$. The mean seasonal precipitation of the central and eastern parts was relatively low compared to the western part of southwest western Australia. It has been established that the streamflow is the chief integrator of the rainfall, especially in these regions where the quantified run-off is dependent on the rainfall and where glacier
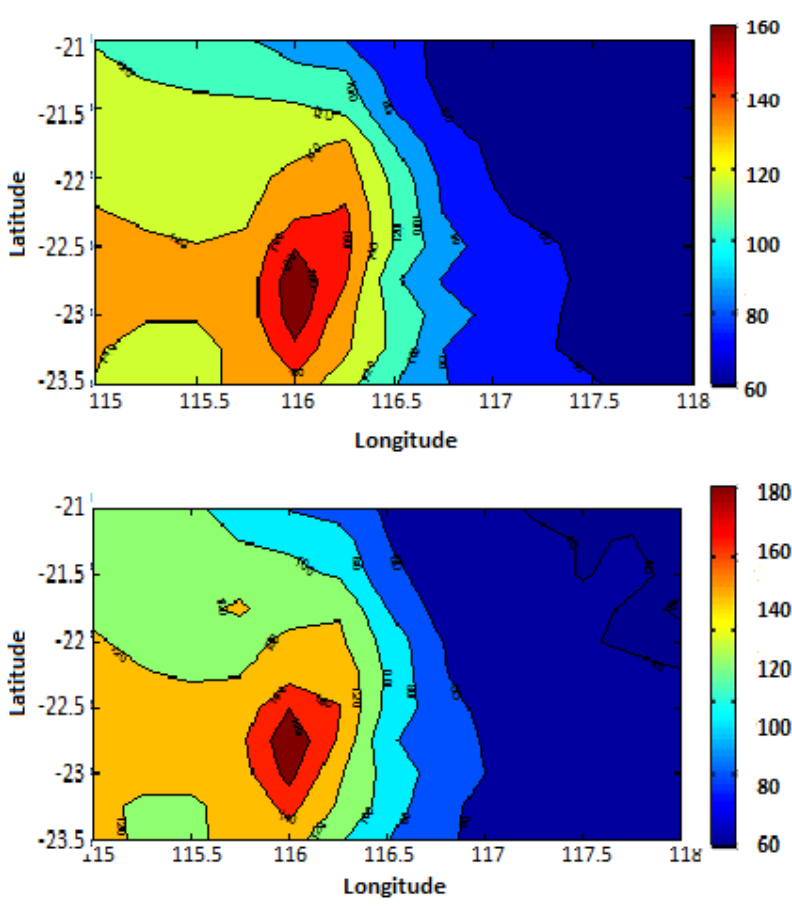

(b)

Figure 9. Composite mean of the early winter (May-August) precipitation rate $\left(\mathrm{mm} \mathrm{month}^{-1}\right)$. (a) The 10 winters in which the IOHP was at a minimum, from 1976 to 2008 (in increasing order of the MCP of the IOHP: 1977, 1988, 1981, 2007, 1951, 1996, 2003, 1985, 1986 and 1978). (b) The 10 winters in which the IOHP was at a maximum, from 1976 to 2008 (in decreasing order of the MCP of the IOHP: 2002, 2000, 1987, 1980, 1979, 2004, 1997, 1982, 1989 and 1993).

systems do not intensify the peak run-off. We conclude that precipitation is dominant in the Australian hydrological cycle. Figure 1 describes the spatial distribution of streamflow catchments over southwestern Australia. This situation indicates that a significant increase occurs in the early winter-time streamflow that is associated with the quantifying rainfall when the MCP of the IOHP is at a minimum. This situation is reversed during the 10 winters with the IOHP at a maximum (Figure $9 \mathrm{~b}$ ), with the seasonal mean rainfall of $160 \mathrm{~mm}$ showing an almost $11 \%$ decrease for the same geographical coordinates; this pattern also persists over all of the region of southwest western Australia. Hence, a low (peak) run-off-streamflow in southwest western Australia appears to be part of a rainfall pattern that affects the western corner and the surrounding region of southwest western Australia.

\subsection{Mean sea level pressure spatial patterns}

The composite analysis (Figure 10) of early wintertime (May-August) MSLP pattern shows remarkably different patterns, in particular, the analysis indicates an inverse relation of IOHP with the streamflow. The mean composite of the SLP fields showed that during the 10 winters when the MCP of the IOHP is minimum the highest streamflow occurs over the rivers of south- 


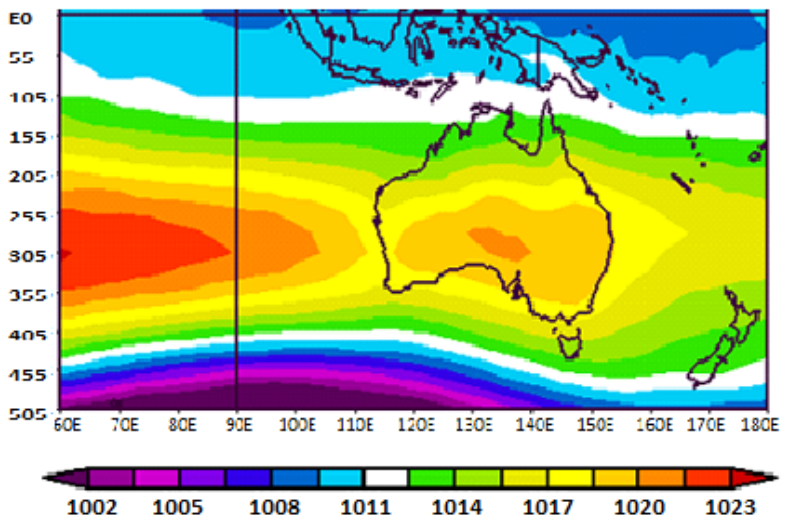

(a)

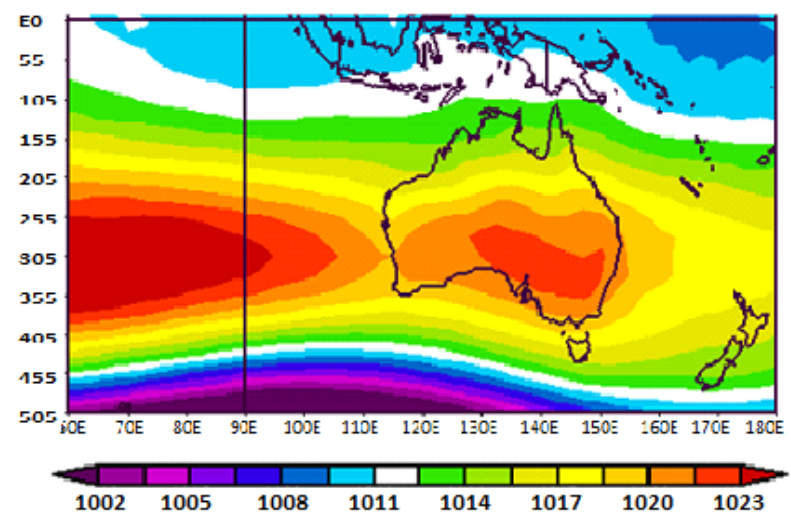

(b)

Figure 10. As for Figure 9, but for the composite mean of the early winter (May-August) mean sea level pressure $\left(\mathrm{mb}\right.$ month $\left.^{-1}\right)$.

western Australia. This means that for the 10 winters where the IOHP is minimum (see Figure 10a) the streamflow is found to be maximum. On the contrary, the case where the 10 winters show maximum IOHP (Figure 10b) the streamflow is found to have minimum value. However, during the 10 winters when the IOHP was minimum, the MSLP across the Indian Ocean and the adjacent land area had closed isobars and equivocal grid lines where values that were equal to or greater than $1023 \mathrm{hPa}$ tended to isolate regions of maximum pressure that were positioned far from the Australian continent, and centered at $20^{\circ} \mathrm{S}$ to $40^{\circ} \mathrm{S}$ and $80^{\circ} \mathrm{E}$ to $120^{\circ} \mathrm{E}$ over subtropical regions of the Indian Ocean. Similarly, there was a band of high pressure in Australia, and particularly in central Australia. The MCP fell between $1016 \mathrm{hPa}$ and $1018 \mathrm{hPa}$, with values $>1020 \mathrm{hPa}$ occurring less than $4 \%$ for the total study region. We note that the MCP of the IOHP over the Australian continent was approximately $1018.5 \mathrm{hPa}$ and was centered over southwest western Australia. The MCP of the isolated region of high pressure across the tropical and subtropical region over the Indian Ocean was around $1020 \mathrm{hPa}$. This high pressure region was situated around the eastern Indian Ocean, centered at $30^{\circ} \mathrm{S}$, which is far from southwest western Australia. Our finding is consistent with Hameed et al. [2011], who showed that when the center of the IOHP is located most to the west across the Indian Ocean, southwest western Australia receives more rainfall. Thus, $75 \%$ of all of the MCP fell between $1016 \mathrm{hPa}$ and $1020 \mathrm{hPa}$, and values greater than $1022 \mathrm{hPa}$ occurred less than $8 \%$ of the time.

The situation was reversed for the 10 winters when the IOHP was at a maximum (when the minimum streamflow occurred over the rivers of southwest western Australia). The MCP of the IOHP was higher by up to $3 \mathrm{hPa}$, in-contrast to the lowest MCP of the IOHP center over the Indian Ocean and the Australian continent, with its dual pattern of high pressure system (Figure 10b). A band of high pressure was positioned nearer to southwest western Australia. The analysis indicates that the early winter-time streamflow is associated with the intensity as well as the zonal movement of the IHOP, which is again consistent with Hameed et al. [2011], who showed that when the MCP of the IOHP was located the most to the east across the Indian Ocean, southwest western Australia received more rain. The composite of the 10 high winters show weaker geostrophic westerly winds around $30^{\circ} \mathrm{S}$ to $33^{\circ} \mathrm{S}$, whereby westerly disturbances provide most of the moisture to western Australia [Hope et al. 2006]. We observed that the MCP of the IHOP over the Australian continent was approximately $1020.5 \mathrm{hPa}$. Another band of the high pressure system was positioned across the Indian Ocean, which covered a large part of the eastern and central Indian Ocean. The MCP of the isolated local pressure maxima across the Indian Ocean was around $1023.5 \mathrm{hPa}$. This second high pressure region was centered at $25^{\circ} \mathrm{S}$ to $40^{\circ} \mathrm{S}$, and the subtropical belt across the Indian Ocean for this center is near to southwestern Australia. Thus, $75 \%$ of all of the MCP fell between $1019.5 \mathrm{hPa}$ and $1023 \mathrm{hPa}$ all of the time. The atmospheric conditions are important in the development of moist inflow from more tropical latitudes [Wright 1974]. Thus the May to July rainfall would be more strongly related to the SLP. It is during this early part of the cool season (May-July) that the greatest rainfall decrease has been observed [IOCI 2004].

\subsection{Vector winds and moisture flux}

The composite analysis of surface vector wind distribution (Figure 11) shows that the SLP spatial patterns for early winter time, which were obtained in Figure 10 , is responsible for variation in surface vector wind over large part of the Indian Ocean. Moreover, the wind circulation is associated with pressure fields that results in geostrophic balance.

The vector winds at surface level are directed parallel to the closed isobars of the IOHP centers. This 

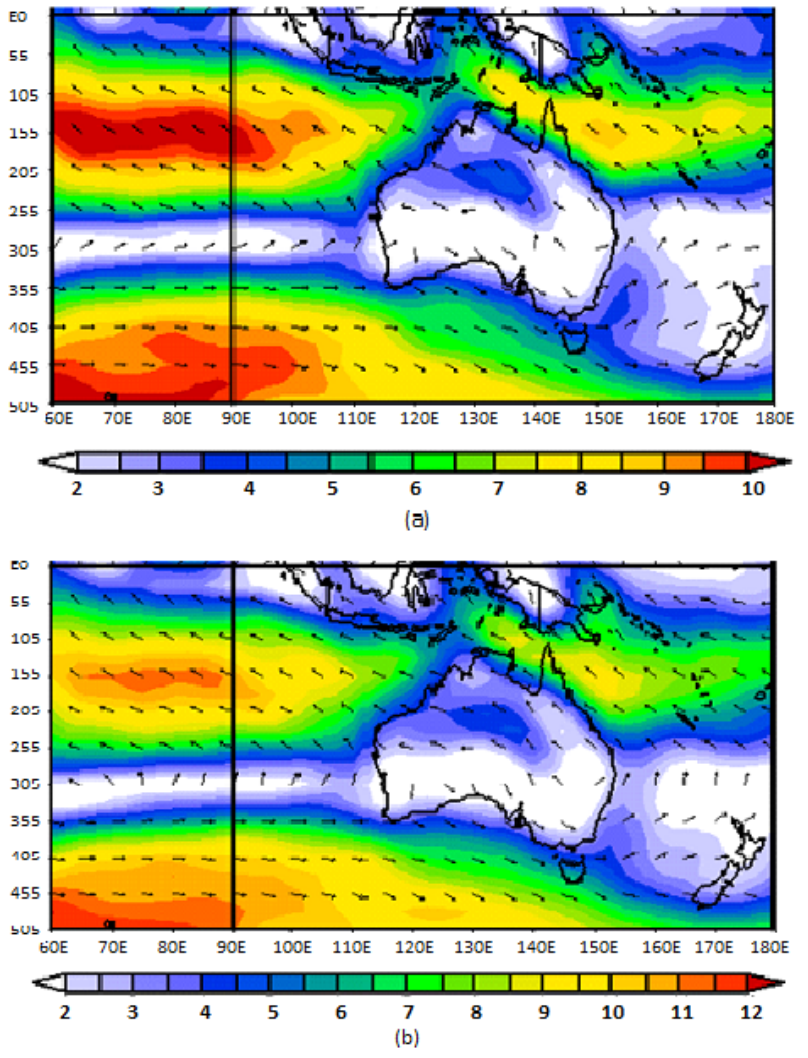

Figure 11. As for Figure 9, but for the composite mean of the early winter (May-August) surface vector wind $\left(\mathrm{m} / \mathrm{s} \mathrm{month}^{-1}\right)$.

shows that for the 10 winters when the IOHP was at a minimum, it is particularly evident that the polar westerlies moved towards southwestern Australia and the southern flank of the Australian continent. These westerlies were particularly strengthened (Figure 11a), which resulted in an eastward shift of the westerlies responsible for the association between the rain-bearing fronts and the polar fronts. The westerlies across the polar belt over the Indian Ocean weakened and provided less moisture, and less streamflow occurred during this period. Similarly, the situation was reversed for the 10 winters when the IOHP was at a maximum, where weak westerly disturbances were weakened and moved towards southwest western Australia (Figure 11b) and the southern flank of the Australian continent. The westerlies across the polar belt over the Indian Ocean weakened and provided less moisture, and less streamflow occurred during this period.

This analysis also provides physical justification of the relationship between rainfall and moisture flux. As mentioned above, the large-scale circulation features, such as the SLP distribution, vector winds and rainfall, are associated with the southwest western Australia run-off. The wind is closely related and influenced by the advection of moisture on the southwest coastal division. The transportation of moisture to southwest western Australia is associated with rainbearing fronts arriving from the Indian Ocean. Inves- tigations into the moisture transport and its variations provides knowledge of the dependence of the southwest western Australia rainfall variability. During the 10 winters when the IOHP was at a maximum, anomalies of $1000 \mathrm{hPa}$ winds were off-shore, nearer the region of southwest western Australia. Similarly, they were onshore during the 10 winters when the IOHP was at a minimum.

\subsection{Anticyclone activity}

Anticyclones having slight equator-ward components of motion, and they are generally concentrated in the subtropics between $25^{\circ} \mathrm{S}$ and $40^{\circ} \mathrm{S}$ [Sinclair 1994, Jones and Simmonds 1994]. We now address the issue of the run-off variability over southwest western Australia using frequency analysis of the Indian Ocean anticyclones [Rehman 2012], from the daily analyses obtained from the National Centers for Environmental Prediction/ National Center for Atmospheric Research. We examined the frequency counts using an automated scheme such that an anticyclone is considered to be present at a grid node on a given day when the SLP becomes equal to, and exceeds, $1020 \mathrm{hPa}$. Here we examined how the early winter-time streamflow was influenced by the mean anticyclone frequency.

Figure 12a shows the spatial frequency distribution of the May-August mean anticyclone frequencies across the Indian Ocean during the 10 winters when the MCP of the IOHP was at a minimum, where the tropical region over the Indian Ocean was dominated by an anticyclone for around 20 days, which represents $80 \%$ of the time. Figure 11a shows that there is a strengthening and coincident eastward (southward) shift of the polar westerlies, which results in more moisture associated with the polar front. This is consistent with Allan and Haylock [1993], who reported that southwest western Australia winter rainfall anomalies can be associated with fluctuations in mid-latitude frontal systems, which result from modulation in the transient anticyclone trough south of Australia.

In contrast, during the 10 winters when the MCP of the IOHP was at a maximum, the tropical region over the Indian Ocean was dominated by an anticyclone for around 26 days, which represents $87 \%$ of the time (Figure 12b). The IOHP strengthened the anticyclone frequency, as well as weakening wind anomalies along Tasmania and southern Australia and the tropical belt over the southern flank of the Australian continent, thereby affecting the tropical ridge that drives winds and moisture onto the southwest coastal division. These findings clearly suggest that there is a strong connection between anticyclones and peak runoff over southwest western Australia. This is consistent 


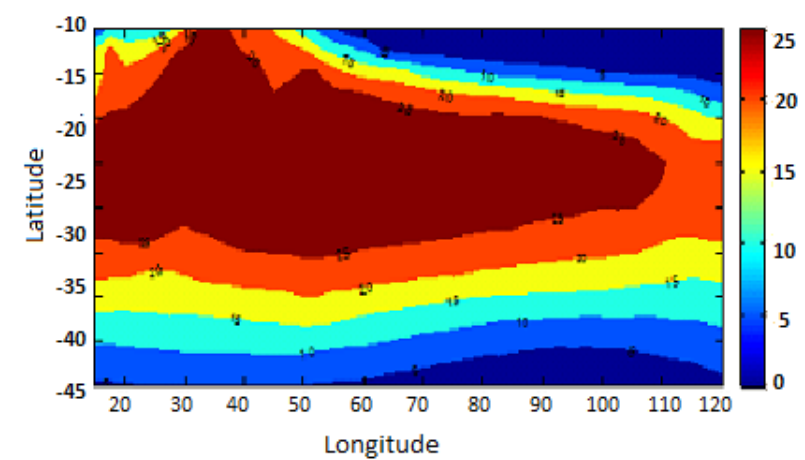

(a)

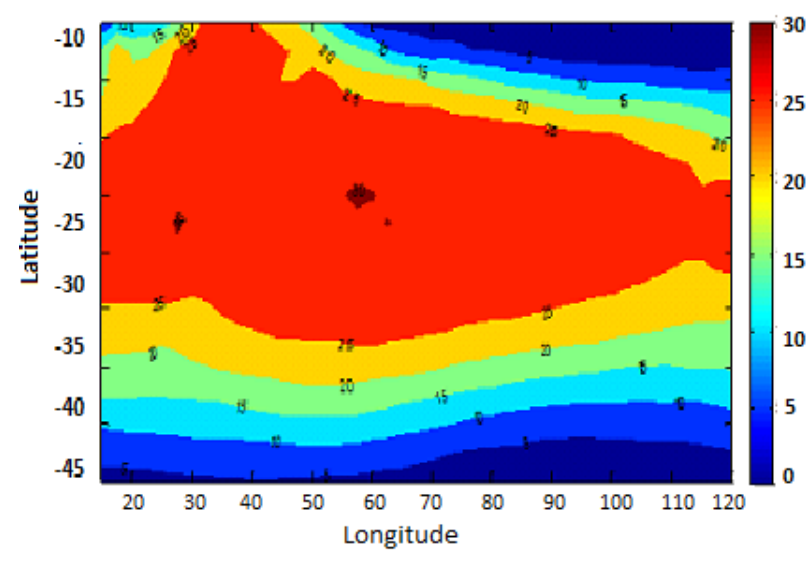

(b)

Figure 12. As in Figure 9, but for the composite mean of the early winter (May-August) mean anticyclone frequency.

with England et al. [2006]. Wind anomalies then develop during the ensuing months (March-May), which amplify to a pronounced large scale acceleration (deceleration) of the Indian Ocean mean anticyclones by wintertime (June-August) during dry (wet) years. During wet years, anomalously low air pressure extends over much of the region, driving deceleration of the Indian Ocean subtropical anticyclone. In the immediate vicinity of southwest western Australia, the winds are anomalously stronger onshore, which forces increased moisture transport into the region.

\section{Conclusions and discussion}

Previous studies have identified increases in sealevel pressures in southwest western Australia as the immediate cause of the ongoing drought in this region. The present study shows that consistent deficiencies in the streamflow with time evolution strongly influence the IOHP and its zonal movement, which leads to severe drought. We have examined this relationship in terms of the dynamics of the IOHP. Specifically, we show that the east-west shifts in the position of this subtropical high pressure significantly influences the early winter streamflow in the southwest coastal division. When the IOHP shifts to the west, the streamflow in southwest western Australia increases, and vice versa. In addition, the streamflow in southwest western Australia is negatively correlated with the area-mean of the IOHP. The IOHP and IOHLN of the IOHP are not significantly correlated with each other.

A significant increase occurs in the early wintertime streamflow associated with quantifying rainfall when the MCP of the IOHP is at a minimum, when a low (peak) run-off-streamflow in southwest western Australia appears to be part of a rainfall pattern that affects the western corner and the adjacent regions of southwest western Australia. The MSLP across the Indian Ocean and the adjacent land area has closed isobars and the westerlies across the polar belt over Indian Ocean are weakened and provide less moisture, with less streamflow occurring during this period. The westerlies across the polar belt over the Indian Ocean weaken and provide less moisture, with less streamflow occurring during the early winter period. On average, there is maximum (minimum) run-off for southwest western Australia where extreme years are characterized by a progressive strengthening of the spatial distribution of the SLP field during progression from January-April and May-August.

A statistical model of the May-August streamflow in southwest western Australia using the IOHP and IOHPLN as independent variables is presented. This explains $29 \%$ of the observed streamflow variance, while the SOI explains only $19 \%$ of the variance, from 1976 to 2008. The lag correlation between the streamflow and the IOHP is -0.45 , while the correlation between the streamflow and the SOI is 0.40 . It is of note that the winter streamflow in southwest western Australia is much more sensitive to variations in the pressure and longitudinal position of the IOHP than it is to fluctuations in the sea surface temperatures, as represented by the Indian Ocean dipole.

Acknowledgements. The data used in this study were obtained from the Western Australian Department of Water, and I thank Jo Gregory, Data Management Officer Water Information for assistance.

\section{References}

Allan, R.J., and M.R. Haylock (1993). Circulation features associated with the winter rainfall decrease in southwestern Australia, Journal of Climate, 6, 1356-1367. Amarasekera, N.A., R.F. Lee, E.R. Williams and E.A.B. Eltahir (1997). ENSO and the natural variability in the flow of tropical rivers, Journal of Hydrology, 200, 24-39.

Chiew, F.H.S., and T.A. McMahon (2002). Global ENSOstreamflow teleconnection, streamflow forecasting and interannual variability, Hydrological Sciences Journal, 47 (3), 505-522. 
Chiew, F.H.S., and T.A. McMahon (2003). El Niño/Southern Oscillation and Australian rainfall and streamflow, Australian Journal of Water Resources, 6, 115-129.

Chiew, F.H.S., S.L. Zhou and T.A. McMahon (2003). Use of seasonal streamflow forecasts in water resources management, Journal of Hydrology, 270, 135-144.

Dettinger, M.D., and H.F. Diaz (2000). Global characteristics of stream flow seasonality and variability, Journal of Hydrometeorology, 1, 289-310.

Doherty, O.M., N. Riemer and S. Hameed (2008). Saharan mineral dust transport into the Caribbean: $\mathrm{Ob}$ served atmospheric controls and trends, J. Geophys. Res., 113, D07211; doi:10.1029/2007JD009171.

Dracup, J.A., and E. Kahya (1994). The relationships Between U.S. Streamflow and La Niña Events, Water Resources Research, 30 (7), 2133-2141.

England, M.H., C.C. Ummenhofer and A. Santoso (2006). Inter-annual rainfall extremes over southwest Western Australia linked to Indian Ocean climate variability, Journal of Climate, 19, 1948-1969

Glantz, M.H., R.W. Katz and N. Nicholls, eds. (1991). Teleconnections Linking Worldwide Climate Anomalies: Scientific Basis and Societal Impact, Cambridge University Press, Cambridge, UK.

Hameed, S., W. Shi, J. Boyle and B. Santer (1995). Proceedings of the First International AMIP Scientific Conference, Monterey, California, WCRP 92, 221.

Hameed, S., and S. Piontkovski (2004). The dominant influence of the Icelandic Low on the position of the Gulf Stream northwall, Geophys. Res. Lett., 31, L09303; doi:10.1029/2004GL019561

Hameed, S., M.J. Iqbal, S. Rehman and D. Collins (2011). Impact of the Indian Ocean High Pressure System On Winter Precipitation over Western Australia and Southwest Western Australia, Australian Meteorological and Oceanographic Journal, 61, 159-170.

Hope, P.K., W. Drosdowsky and N. Nicholls (2006). Shifts in the synoptic systems influencing southwest Western Australia, Climate Dynamics, 26, 751-769.

IOCI, Indian Ocean Climate Initiative - Western Australia (2004). 18th panel meeting sets agenda to broaden dialogue on climate change, Bulletin no. 4; http: / / www.ioci.org.au/pdf/IOCI_Bulletin4.pdf.

Jones, D.A., and I. Simmonds (1994). A Climatology of Southern Hemisphere Anticyclones, Climate Dynamics, 10, 333-348.

Jones, D.A., W. Wang and R. Fawcett (2009). High-quality spatial climate data-sets for Australia, Australian Meteorological and Oceanographic Journal, 58, 233-248.

Kahya, E., and J.A. Dracup (1993). U.S. Streamflow Patterns in Relation to the El Niño Southern Oscilla- tion, Water Resources Research, 29 (8), 2491-2503.

Kahya, E., and M.C. Karabork (2001). The analysis of El Niño and La Niña signals in streamflows of Turkey, International Journal of Climatology, 21, 1231-1250.

Kalnay, E., and coauthors (1996). The NCEP/NCAR 40-Year Reanalysis Project, Bull. Amer. Meteor. Soc., 77, 437-471.

Legates, D.R. (1993). The effect of domain shape on principal components analyses: A reply, International Journal of Climatology, 13 (2), 219-228.

Li, F., L.E. Chambers and N. Nicholls (2005). Relationships between rainfall in the southwest of Western Australia and near-global patterns of sea-surface temperature and mean sea-level pressure variability, Australian Meteorological Magazine, 54 (1), 23-33.

Piechota, T.C., and J.A. Dracup (1996). Drought and regional hydrologic variation in the United States: associations with El Niño/southern oscillation, Water Resources Research, 32 (5), 1359-1373.

Piechota, T.C., J.A. Dracup, F.H.S. Chiew and T.A. McMahon (1997). Seasonal streamflow forecasting in eastern Australia and the El Niño southern oscillation, Water Resources Research, 34, 3035-3044.

Rehman, S., and M.J. Iqbal (2011). The relationship between Indian Ocean High Pressure and runoff variability in the Donnelly River catchment in southwest western Australia: a case study, The Nucleus, 48 (3), 213-222.

Rehman, S. (2012). Modelling the impact of Indian Ocean High Pressure on Western Australia climate variability and streamflow, PhD thesis, University of Karachi, Karachi, Pakistan.

Richman, M.B. (1993). Comments on: 'The effect of domain shape on principal components analyses', International Journal of Climatology, 13 (2), 203-218.

Riemer, R., O.M. Doherty and S. Hameed (2006). On the variability of African dust transport across the Atlantic, Geophys. Res. Lett., 33, L13814.

Ropelewski, C.F., and M.S. Halpert (1987). Global and regional scale precipitation patterns associated with the El Niño/Southern Oscillation, Monthly Weather Review, 115, 1606-1626.

Ropelewski, C.F., and M.S. Halpert (1989). Precipitation patterns associated with the high index phase of the southern oscillation, Journal of Climate, 2, 268-284.

Santer, B.D. (1988). Regional validation of general circulation models, Ph.D. Thesis, University of East Angelia, Norwich, England.

Simpson, H.J., M.A. Cane, A.L. Herczeg and J.H. Simpson (1993). Annual river discharges in Southeastern Australia related to the El Niño southern oscillation forecasts of sea surface temperatures, Water Resources Research, 29 (11), 3671-3680. 
Sinclair, M R. (1994). An objective cyclone climatology for the Southern Hemisphere, Monthly Weather Review, 122, 2239-2256.

Uvo, C.B., and N.E. Graham (1998). Seasonal runoff forecasts for northern South America: a statistical model, Water Resources Research, 34 (12), 3515-3524.

Wang, G., and E.A.B. Eltahir (1999). Use of ENSO information in medium and long-range forecasting of Nile floods, Journal of Climate, 12, 1726-1737.

Western Australian Department of Water (2009). Streamflow trends in south-west Western Australia, Surface water hydrology series - Report no. HY32, 79 pp.

Wright, P.B. (1974). Seasonal rainfall in southwestern Australia and the general circulation, Monthly Weather Review, 102, 219-32.

${ }^{\star}$ Corresponding author: Saqib-Ur-Rehman,

Iqra University, Department of Computer Science, North Naz-

imabad, Karachi, Pakistan; email: mathematician60@hotmail.com.

(C) 2014 by the Istituto Nazionale di Geofisica e Vulcanologia. All rights reserved. 